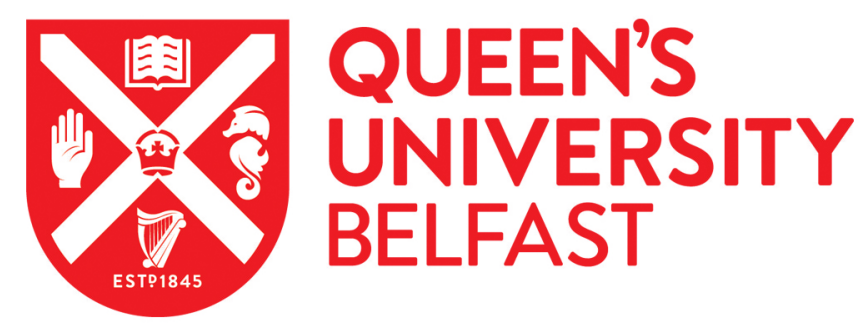

\title{
Statin use and survival in colorectal cancer: Results from a population-based cohort study and an updated systematic review and meta-analysis
}

Gray, R. T., Coleman, H. G., Hughes, C., Murray, L. J., \& Cardwell, C. R. (2016). Statin use and survival in colorectal cancer: Results from a population-based cohort study and an updated systematic review and metaanalysis. Cancer Epidemiology, 45, 71-81. https://doi.org/10.1016/j.canep.2016.10.004

\section{Published in:}

Cancer Epidemiology

\section{Document Version:}

Peer reviewed version

Queen's University Belfast - Research Portal:

Link to publication record in Queen's University Belfast Research Portal

\section{Publisher rights}

Copyright 2016 Elsevier Ltd. All rights reserved.. This manuscript version is made available under the CC-BY-NC-ND 4.0 license $\mathrm{http}: / /$ creativecommons.org/licenses/by-nc-nd/4.0/ which permits distribution and reproduction for non-commercial purposes, provided the author and source are cited.

\section{General rights}

Copyright for the publications made accessible via the Queen's University Belfast Research Portal is retained by the author(s) and / or other copyright owners and it is a condition of accessing these publications that users recognise and abide by the legal requirements associated with these rights.

Take down policy

The Research Portal is Queen's institutional repository that provides access to Queen's research output. Every effort has been made to ensure that content in the Research Portal does not infringe any person's rights, or applicable UK laws. If you discover content in the Research Portal that you believe breaches copyright or violates any law, please contact openaccess@qub.ac.uk. 


\section{TITLE}

Statin use and survival in colorectal cancer: results from a population-based cohort study and an updated systematic review and meta-analysis.

\section{RUNNING HEAD}

Statin use and survival in colorectal cancer.

\section{AUTHORS}

Ronan T. Graya, Helen G. Colemana, Carmel Hughes ${ }^{b}$, Liam J. Murraya, Chris R. Cardwella

\section{INSTITUTIONS}

${ }^{a}$ Cancer Epidemiology and Health Services Research Group, Centre for Public Health, Queen's University Belfast, Royal Victoria Hospital, Belfast BT12 6BA, Northern Ireland, UK

bSchool of Pharmacy, Queen's University Belfast, 97 Lisburn Road, Belfast BT9 7BL, Northern Ireland, UK

\section{CORRESPONDING AUTHOR}

Mr Ronan T. Gray 
MB BCh (Hons), MSc, MRCS

Cancer Epidemiology and Health Services Research Group, Centre for Public Health, Queen's University Belfast, Royal Victoria Hospital, Belfast, BT12 6BA, Northern Ireland, UK.

Email: rgray05@qub.ac.uk

Telephone: +44 (0)289097 1606

\section{ABBREVIATIONS}

$\mathrm{Cl}$ - Confidence interval

CRC - Colorectal cancer

DDD - Daily defined dose

HR - Hazard ratio 


\begin{abstract}
Background

The aim of this study was to investigate the association between statin use and survival in a population-based colorectal cancer (CRC) cohort and perform an updated meta-analysis to quantify the magnitude of any association.
\end{abstract}

\title{
Methods
}

A cohort of 8,391 patients with newly diagnosed Dukes' A-C CRC (2009-2012) was identified from the Scottish Cancer Registry. This cohort was linked to the Prescribing Information System and the National Records of Scotland Death Records (until January 2015) to identify 1,064 colorectal cancer-specific deaths. Adjusted hazard ratios (HRs) and 95\% confidence intervals (Cls) for cancer-specific mortality by statin use were calculated using time dependent Cox regression models. The systematic review included relevant studies published before January 2016. Meta-analysis techniques were used to derive combined HRs for associations between statin use and cancer-specific and overall mortality.

\section{Results}

In the Scottish cohort, statin use before diagnosis (HR=0.84, 95\% Cl 0.75-0.94), but not after (HR=0.90, 95\% Cl 0.77-1.05), was associated with significantly improved cancer-specific mortality. The systematic review identified 15 relevant studies. In the meta-analysis, there was consistent $\left(\mathrm{I}^{2}=0 \%\right.$, heterogeneity $\left.\mathrm{P}=0.57\right)$ evidence of a reduction in cancer-specific mortality with statin use before diagnosis in 6 studies $(\mathrm{n}=86,622$, pooled $\mathrm{HR}=0.82,95 \% \mathrm{Cl} 0.79-0.86)$ but this association was less apparent and more heterogeneous $\left(\mathrm{I}^{2}=67 \%\right.$, heterogeneity $\left.\mathrm{P}=0.03\right)$ with statin use after diagnosis in 4 studies ( $n=19,152$, pooled $\mathrm{HR}=0.84,95 \% \mathrm{Cl}$ 0.68-1.04). 


\section{Conclusion}

In a Scottish CRC cohort and updated meta-analysis there was some evidence that statin use was associated with improved survival. However, these associations were weak in magnitude and, particularly for post-diagnosis use, varied markedly between studies.

\section{KEY WORDS}

Hydroxymethylglutaryl-CoA Reductase Inhibitors; Colorectal Neoplasms; Survival; Pharmacoepidemiology; Review, Systematic; Meta-Analysis 


\section{INTRODUCTION}

It is currently estimated that there are 1.4 million incident cases of colorectal cancer (CRC) per year worldwide. ${ }^{1}$ In the United Kingdom (UK), CRC is the second most common cause of cancer death with an associated 5-year survival of $50-55 \%{ }^{2,3}$ Unfortunately there have been no major advances in the treatment of locally advanced CRC since the MOSAIC study (oxaliplatin in addition to standard chemotherapy) was published over a decade ago, ${ }^{4}$ therefore research into novel agents or novel use of existing agents is required. 5,6

Like aspirin, statins have been identified as potential novel anti-cancer agents that are cost-effective and safe to administer. ${ }^{7,8}$ They inhibit the mevalonate pathway and have been shown to have anti-cancer effects in-vitro. ${ }^{9}$ Our research group previously reported an association between both pre- and post-diagnostic statin use and improved survival in CRC using observational data. ${ }^{10}$ However, not all observational studies assessing the role of statins in CRC survival support our findings. ${ }^{8,10-19} \mathrm{~A}$ recent meta-analysis of these studies suggests the associated reduction in cancerspecific mortality was limited to pre-diagnostic statin users. ${ }^{20}$ However two other meta-analyses conclude that the benefit is observed for both pre- and postdiagnostic statin users. ${ }^{21,22}$ Importantly though, none of these meta-analyses capture all of the currently available data and they all include hazard ratios for postdiagnostic statin use from one study ${ }^{13}$ at risk of immortal time bias. ${ }^{23}$ To clarify the association between post-diagnostic statin use and CRC survival we describe a further observational study using an independent population-based UK dataset. We also performed an updated systematic review and meta-analysis to include all additional data for post-diagnostic use that is not at risk of immortal time bias. 


\section{MATERIALS AND METHODS}

\subsection{Cohort study}

\subsubsection{Data source}

The study utilised linkages between national datasets from Scotland including the Scottish Cancer Registry (SMR06), the Prescribing Information System (available from January 2009 to January 2015), ${ }^{24}$ the General / Acute Inpatient and Day Case dataset (SMR01), the Outpatient Attendance dataset (SMR00) and the National Records of Scotland Death Records. A more detailed description of these data resources is described in Supplementary File 1. Linkages between data sources were conducted using the Community Health Index number (unique to individuals in Scotland). The Privacy Advisory Committee of the National Health Service (NHS) National Services Scotland (NSS) approved the study.

\subsubsection{Study population}

A cohort of newly diagnosed CRC patients was identified on the basis of a Scottish Cancer Registry recorded primary diagnosis of CRC (comprising ICD codes of the colon C18 or rectum C20 including the recto-sigmoid junction C19) between January 2009 and December 2012. Cohort members with a previous Scottish Cancer Registry cancer diagnosis (after January 1999), apart from in situ neoplasms and non-melanoma skin cancers, were excluded.

As post-diagnostic medication usage is unlikely to influence survival in cases with incident metastatic disease, the analysis of medication use after diagnosis was restricted to patients with incident Dukes' A-C disease. Deaths were identified from 
National Records of Scotland with coverage up to 1st January 2015 (or from Scottish Cancer Registry death records) with CRC-specific deaths defined as those with underlying cause of death ICD code C18, C19, C20, C21 (anus) or C26 (other and ill-defined digestive organs). Deaths in the first year after CRC diagnosis were removed, this restriction reduces the likelihood of including patients who were not recurrence-free at exposure. ${ }^{25}$ Patients were therefore followed from one year after CRC diagnosis to death, the date they left Scotland or $1^{\text {st }}$ January 2015 , whichever occurred first.

\subsubsection{Exposure data}

Statins dispensed in the community (identified from the Prescribing Information System) consisted of all medications in the Statins section of the British National Formulary (Section 2.12). ${ }^{26}$ A quantity of 28 tablets was assumed for the less than $0.1 \%$ of prescriptions where quantity was deemed incorrect. Daily defined doses (DDD) in each prescription were calculated by multiplying the quantity by strength (in mg) and dividing by the World Health Organization defined DDD (in mg) for individual statins as defined by the). ${ }^{27}$ Statin use was investigated as a time-varying covariate (patients were initially considered non-users and then users after a lag of 6 months after their first statin prescription)..$^{23}$ The use of a lag is recommended ${ }^{25}$ and in this study prescriptions in the 6 month period prior to death were not considered as these may reflect end of life treatment (in sensitivity analyses the duration of this lag was varied). Dose-response analyses were conducted with individuals considered non-users prior to 6 months after first use, a short term user between 6 months after first use and 6 months after the $12^{\text {th }}$ prescription (or 365 DDDs) and a longer term user after this time. 


\subsubsection{Covariates}

Data available from the Scottish Cancer Registry included Dukes' stage, histological grade and surgery, chemotherapy and radiotherapy in the six months after diagnosis. Comorbidities that contribute to the Charlson index were determined prior to diagnosis based upon ICD10 diagnosis codes, as described previously, ${ }^{28}$ in Scottish hospital inpatient (SMR01) and outpatient data (SMR00). A deprivation measure was determined using the 2009 Scottish Index of Multiple Deprivation based upon postcode of residence. ${ }^{29}$ Low-dose aspirin use was determined from dispensing records.

\subsubsection{Statistical analysis}

In the main analysis, time-dependent Cox regression models were used to calculate hazard ratios (HRs) for CRC-specific death and 95\% confidence intervals (95\% Cl) for post-diagnostic statin users compared with non-users using a time-varying covariate as described previously. Deaths from other causes were censored in cancer-specific analyses. Adjusted analyses were conducted including the following potential confounders: sex, age, year of diagnosis, deprivation (in fifths), grade, site (colon or rectal), Dukes' stage, surgery (within 6 months of diagnosis), radiotherapy (within 6 months of diagnosis), chemotherapy (within 6 months of diagnosis), comorbidities (dichotomised as absent or present prior to diagnosis, including acute myocardial infarction, congestive heart failure, peripheral vascular disease, cerebral vascular accident, pulmonary disease, peptic ulcer, liver disease, diabetes, renal disease) and aspirin usage (as time-varying covariate). Other commonly prescribed medications with potential anti-cancer effects (metformin, drugs affecting the reninangiotensin system and beta-blockers) were not included in the final models, as they 
did not alter the hazard ratio estimates. Analyses were conducted by number of prescriptions, number of DDDs and type of statin and repeated for all-cause mortality. Subgroup analyses were conducted by site (colon or rectal), stage (I-III), treatment (surgery alone versus surgery and adjuvant therapy) and finally for postdiagnostic statin users, de novo versus pre- and post-diagnostic statin use.

Sensitivity analysis was conducted by increasing the lag to 1 year. A simplified analysis was also performed using Cox regression to compare statin users to nonusers in the first year after CRC diagnosis in individuals living more than 1 year after diagnosis; this controls for immortal time bias without requiring time-varying covariates. ${ }^{30}$ Finally, an analysis was conducted based upon statin prescriptions in the year prior to diagnosis (excluding patients diagnosed in 2009 for whom a full year of prescription records prior to diagnosis may not be available), not excluding deaths in the first year after diagnosis and including all CRC patients regardless of Dukes' stage. To avoid overadjustment this analysis did not adjust for stage and grade, or restrict the cohort to Dukes' stage A to C disease, because these variables could be on the causal pathway for the association between pre-diagnostic statin use and CRC-specific mortality. ${ }^{31,32}$ For comparison between studies a fully adjusted model was also included. Finally, as the prevalence of commonly prescribed medications may increase in the period before cancer diagnosis an alternative definition of prediagnostic statin use in the 12-month period one to two years prior to diagnosis was also assessed (this definition requires the exclusion of patients diagnosed in 2009 and 2010). 


\subsection{Systematic review and meta-analysis}

\subsubsection{Search strategy}

The review protocol was undertaken according to the principles recommended by the Preferred Reporting Items for Systematic Reviews and Meta-Analyses (PRISMA) ${ }^{33}$ and Meta-analysis of Observational Studies in Epidemiology (MOOSE) group ${ }^{34}$ statements. It was registered with the PROSPERO international prospective register of systematic reviews (http://www.crd.york.ac.uk/PROSPERO, registration number CRD42015017915). A systematic search of the literature was performed using Medline (US National Library of Medicine, Bethesda, Maryland, USA), Embase (Reed Elselvier PLC, Amsterdam, Netherlands) and Web of Science (Thompson Reuters, New York, USA). The search encompassed all studies published from database inception to January 12 2016. Keywords and Medical Subject Headings (MeSH) relating to statins and $\mathrm{CRC}$ were used following the strategies detailed in Supplementary File 1. References of all eligible studies were also searched for additional relevant studies.

\subsubsection{Study selection and eligibility criteria}

Two independent reviewers (R.T.G. and H.G.C.) screened all titles and abstracts to identify eligible studies. Full-text manuscripts were reviewed in cases where the title and abstract provided insufficient information to determine eligibility. Disagreements were resolved after discussion with a third party (L.J.M.). Studies were considered for inclusion if (i) they identified a cohort of CRC patients in which exposure to statin treatment was measured and recorded and (ii) they determined an estimate of progression of CRC (i.e. overall, cancer-specific, recurrence-free, progression-free or disease free survival) in a statin user group compared with non-users using 
measures of effect or association (HR, relative risk $(\mathrm{RR})$ or odds ratio $(\mathrm{OR}))$ and corresponding $95 \% \mathrm{Cl}$, or enough information to allow these to be calculated. Abstracts and non-English language articles were included if they met the criteria above. Authors were contacted for further information when required. Results from the current cohort study were also included in the final pooled analyses.

\subsubsection{Data extraction and study quality assessment}

Standardised data extraction forms were used to collect information on the variables listed in Supplementary File 1 (R.T.G). When the information was not clear this was discussed with a second investigator (H.G.C). The methodological quality of the studies included in the meta-analysis was assessed (R.T.G.) using the NewcastleOttawa scale for cohort studies ${ }^{35}$ and the Cochrane risk of bias tool for randomised controlled trials (RCTs). ${ }^{36}$ When the judgement of the domain was not immediately clear it was discussed with a second investigator (H.G.C. or C.R.C.).

\subsubsection{Statistical analysis}

The statistical analysis was conducted using Review Manager (RevMan [Computer program]. Version 5.3. Copenhagen: The Nordic Cochrane Centre, The Cochrane Collaboration, 2014). A random effects model was used to produce pooled estimates from the fully adjusted HRs and Cls of included studies. If these were not available estimates of the HR and standard error were produced using the indirect method proposed by Parmar et al. ${ }^{37}$ Meta-analyses were conducted separately on statin use before and after diagnosis. Study outcomes for post-diagnostic statin use deemed to be at risk of immortal time bias, where the exposed group acquire follow-up from a fixed time point (such as diagnosis date) but do not actually commence statin 
therapy to later in their follow-up, were not included in the pooled analyses. ${ }^{23}$ Between-study heterogeneity was assessed using the Cochrane Q statistic ( $\chi^{2}$ test) and the $\mathrm{I}^{2}$ statistic. ${ }^{38}$ Funnel plot asymmetry was visually assessed to determine the potential for publication bias. A number of a priori subgroup analyses were considered including tumour location (colon versus rectum), sex, age (>65 years versus $\leq 65$ years) and disease stage. Finally, sensitivity analyses were performed by systematically removing each individual study in order to assess its effect on the pooled result estimates and accompanying heterogeneity. 


\section{RESULTS}

\subsection{Cohort study}

\subsubsection{Patient cohort}

A total of 8,391 incident Dukes' A to C CRC cases met the inclusion criteria (Supplementary Figure 1), in which there was, on average, 2.4 years of exposurerelated follow-up starting one year after diagnosis $(\mathrm{sd}=1.3$, minimum $=0$, maximum $=5$ years). Patient characteristics by statin use are shown in Table 1. Statin users were more likely to be older and male. Stage and grade were generally similar by statin use, but a smaller proportion of statin users compared with statin non-users had Dukes' C disease (post-diagnostic use $32.5 \%$ versus $36.2 \%$ respectively). Statin users were more likely to have comorbidities (particularly cerebrovascular disease, diabetes and myocardial infarction) and use concomitant aspirin, but a smaller proportion received adjuvant chemotherapy.

\subsubsection{Association between post-diagnostic statin use and survival}

Overall, there was no statistically significant reduction in CRC-specific mortality when post-diagnostic statin users were compared with statin non-users (Table 2).

Similarly, there was no evidence of a dose-response association when exposure was investigated using DDDs. The absence of an association with CRC-specific survival persisted when simvastatin was assessed and after adjustment for potential confounders. Similar results were observed for adjusted all-cause mortality in terms of marginal non-significant reductions in mortality. 


\subsubsection{Sensitivity / subgroup analyses}

Sensitivity / subgroup analyses are shown in Table 3. Stratifying by tumour location, overall mortality was reduced for post-diagnostic statin users compared to statin nonusers in patients with colon cancer $(\mathrm{HR}=0.85,95 \% \mathrm{Cl} 0.74$ to 0.98$)$. However, this subgroup benefit was less apparent for CRC-specific mortality $(\mathrm{HR}=0.88,95 \% \mathrm{Cl}$ 0.74 to 1.06). There was some evidence of reduced CRC-specific mortality for statin users compared to non-users when the analysis was restricted to stage II tumours but this was only of marginal statistical significance $(\mathrm{HR}=0.75,95 \% \mathrm{Cl} 0.56$ to 1.00 , Supplementary Table 1). There was no evidence of a differential association when cases were stratified by treatment with surgery alone compared to those receiving additional adjuvant therapies (Supplementary Table 1). Increasing the lag period to one year did not alter the results for post-diagnostic statin use and CRC-specific mortality (adjusted $\mathrm{HR}=0.93,95 \% \mathrm{Cl} 0.79$ to 1.08 ). Repeating the analysis using a simplified 1 year analysis also did not demonstrate a survival benefit for postdiagnostic statin use (Table 3). When post-diagnostic statin use versus non-use was stratified by de novo compared to prior statin use, de novo post-diagnostic statin users had a more pronounced reduction in cancer-specific and overall mortality. However, the interactions for CRC-specific and overall mortality ( $P$ for interaction $=0.34$ and 0.35 , respectively) were not significant. Finally, in contrast to the non-significant association observed for post-diagnostic statin use, CRC-specific mortality and overall mortality were significantly improved by $16 \%(\mathrm{HR}=0.84,95 \% \mathrm{Cl}$ 0.75 to 0.94$)$ and $11 \%(\mathrm{HR}=0.89,95 \% \mathrm{Cl} 0.80$ to 0.98$)$ respectively comparing prediagnostic statin users (in the year prior to diagnosis) with statin non-users. These associations were not significantly altered when the definition of pre-diagnostic use 
was changed to include any use in the one year period one to two years prior to diagnosis (results not shown).

\subsection{Systematic review and meta-analysis}

\subsubsection{Search results and study characteristics}

Fifteen studies were deemed eligible for inclusion in the final review after screening 1192 titles and abstracts (Figure 1). There was one RCT, ${ }^{39}$ six prospective population-based studies, ${ }^{8,10,11,16,18,40}$ two cohorts within RCTs, ${ }^{12,15}$ one prospective cohort within a population-based case-control study ${ }^{13}$ and five retrospective hospitalbased cohorts(Table 4). 14,17,19,41,42 Seven studies assessed stage I-IV disease, ${ }^{11,13,14,17-19,40}$ three assessed stage I-III disease, ${ }^{10,16,41}$ two stage III disease only, ${ }^{15,42}$ two stage IV disease only, ${ }^{12,39}$ and one did not report stage. ${ }^{8}$ Two studies reported outcomes for only rectal cancer patients, ${ }^{14,41}$ one study consisted of only male subjects ${ }^{17}$ while another related to patients with diabetes mellitus only. ${ }^{18}$ Eleven studies reported outcomes for post-diagnostic statin use $\mathrm{e}^{10-15,18,19,39,40,42}$ and six reported pre-diagnostic statin use..$^{8,10,13,16,17,41}$ The methodological quality of these 15 studies ( $n=14$ observational, $n=1$ RCT) was evaluated using relevant risk of bias tools (Supplementary Table 2 and 3). In addition to these studies, we also included the results from our own population-based cohort study (described above).

\subsubsection{Post-diagnostic statin use}

Four studies with 19,152 patients reported CRC-specific mortality in post-diagnostic statin users compared to statin non-users but only two of them, the current study and Cardwell et al, ${ }^{10}$ assessed statin use as a time-varying covariate. The pooled HR 
was $0.84(95 \% \mathrm{Cl} 0.68$ to 1.04$)$ with evidence of significant heterogeneity (heterogeneity $\mathrm{P}=0.03 ; \mathrm{I}^{2}=67 \%$ ) (Figure $2 \mathrm{~A}$ ). Removing the study by Cardwell et al. ${ }^{10}$ in sensitivity analysis reduced this statistical heterogeneity but moved the association closer to null (Supplementary Table 4).

Twelve studies reported overall mortality in relation to post-diagnostic statin use but the HR reported by Lakha et al. ${ }^{13}$ was excluded as it has previously been identified as being at risk of immortal time bias. ${ }^{10,20}$ Eleven studies (21,030 patients) were subsequently included in the pooled analysis for which the HR was $0.84(95 \% \mathrm{CI}$ 0.73 to 0.98 ). Again, there was a high level of statistical heterogeneity (heterogeneity $\mathrm{P}=0.0004 ; \mathrm{I}^{2}=69 \%$ ) (Figure $2 \mathrm{~B}$ ). There was also methodological heterogeneity amongst the studies included in this analysis. Only four studies (the current study, Cardwell et al., ${ }^{10}$ Voorneveld et al. ${ }^{40}$ and Zanders et al. ${ }^{18}$ ) assessed post-diagnostic statin use as a time-varying covariate, one considered a diabetic cohort only ${ }^{18}$ and a further two assessed the role of statins in stage IV disease only..$^{12,39}$ Removing individual studies in sensitivity analysis did not markedly alter the result or associated heterogeneity for overall mortality and post-diagnostic statin use (Supplementary Table 4).

\subsubsection{Pre-diagnostic statin use}

Six studies with 86,622 patients reported CRC-specific mortality in pre-diagnostic statin users compared to statin non-users. The pooled HR was 0.82 (95\% Cl 0.79 to 0.86 ) with no evidence of heterogeneity (heterogeneity $P=0.57 ; I^{2}=0 \%$ ) (Figure $3 A$ ). Statin exposure was determined through linkage to dispensing or prescribing 
databases in all of the studies included in this pooled analysis and four of the six were large population-based studies.

Six studies (44,026 patients) also reported overall mortality in relation to prediagnostic statin use. The pooled HR for overall mortality was $0.85(95 \% \mathrm{Cl} 0.76$ to 0.95) although there was evidence of significant heterogeneity in this analysis (heterogeneity $\mathrm{P}=0.0009 ; \mathrm{I}^{2}=76 \%$ ) (Figure 3B). There was also greater methodological heterogeneity associated with this analysis as one study ${ }^{41}$ relied on medical record review rather than data linkage and only three were prospective population-based cohorts (current study, Cardwell et al. ${ }^{10}$ and Shao et al. ${ }^{16}$ ). The heterogeneity associated with the pooled analysis for pre-diagnostic statin use and overall mortality reduced from $76 \%$ to $48 \%$ when the only study associated with increased mortality was removed (Supplementary Table 4). Removing the other studies individually had no significant impact on the result or associated heterogeneity.

\subsubsection{Subgroup analyses and publication bias}

Survival estimates stratified by age, sex, stage and tumour location were not consistently reported therefore the planned subgroup analysis could not be reliably performed. Funnel plots showed no evidence of asymmetry for cancer-specific or overall mortality in pre- or post-diagnostic statin use (Supplementary Figure 2). 


\section{DISCUSSION}

In a large Scottish cohort of CRC patients we identified some evidence of an inverse association between CRC-specific mortality and statin use before diagnosis but less evidence of an association with statin use after diagnosis. In particular, while de novo post-diagnostic statin use was associated with reduced cancer-specific mortality in a subgroup analysis, this association was based on relatively few events and the interaction term for this stratification was not statistically significant. An updated systematic review and meta-analysis was subsequently performed which demonstrated an association with relatively small reductions in cancer-specific and all-cause mortality with statin use before and after diagnosis. However, these associations generally lacked consistency and the association between cancerspecific mortality and post-diagnostic statin use did not reach statistical significance.

We previously reported an association between improved survival outcomes and post-diagnostic statin use in a cohort of 7,657 patients within the UK National Cancer Data Repository. ${ }^{10}$ However, despite using very similar methodology, the association with reduced mortality was smaller and non-significant in this current Scottish cohort of 8,391 patients. In addition to the possibility of differences in unknown lifestyle factors, one potential explanation for the failure to demonstrate a significant inverse association between post-diagnostic statin use and mortality in the current study is that it is more contemporaneous (2009-2012 versus 1998-2009). In more recent years important changes in the detection and management of CRC occurred including the full implementation of the bowel cancer screening programme in Scotland in $2009^{43}$ and the availability of oxaliplatin-based adjuvant chemotherapy from $2006 .{ }^{44}$ It is possible that undergoing screening (with the potential to have an 
earlier stage tumour) or receiving oxaliplatin-based chemotherapy could be associated with statin use. Therefore, potential confounding by these factors could contribute to the different findings observed in our studies.

The results of other studies assessing post-diagnostic statin use are similarly heterogeneous (12 67\%-69\%) and may represent the absence of a standardised methodological approach. The numerous different methods could explain some of this heterogeneity. For example, the use of patient self-reporting measures to determine statin use potentially introduces recall bias and limiting the study population to stage IV disease or diabetic patients reduces external validity. Finally, only four studies reported cancer-specific mortality in post-diagnostic statin users compared to 11 studies reporting overall mortality. The inverse association with survival outcomes and post-diagnostic statin use was only statistically significant for overall mortality in the subsequent meta-analysis. However, as this could reflect noncancer related mortality, further studies assessing cancer-specific mortality are required.

In comparison to the results for post-diagnostic statin use, the significant association between improved survival outcomes and pre-diagnostic statin use observed in the UK National Cancer Data Repository cohort ${ }^{10}$ persisted in the Scottish cohort study, albeit the magnitude of the effect was smaller. The subsequent pooled analysis demonstrated pre-diagnostic statin use was associated with an $18 \%$ reduction in cancer-specific mortality. The absence of statistical heterogeneity in this analysis contrasts with the other pooled analyses and could represent a more homogeneous 
methodological approach. In this case, the majority of studies used large-scale population-based designs and utilised prescribing or dispensing database information. Overall there were also four times as many patients in the precompared to post-diagnostic pooled analysis for cancer-specific mortality. However, the consistent association observed for pre-diagnostic users is perhaps less clinically useful, as it is difficult to intervene before diagnosis, whereas an association with post-diagnostic use could represent the potential for use as a novel adjuvant agent.

It remains unclear if the molecular phenotype of CRC developing in pre-diagnostic statin users is different to statin non-users and whether this difference conveys a survival benefit. While no benefit for statin use was identified when survival analyses were stratified by KRAS status ${ }^{11,15}$ or $\mathrm{MSI}^{11}$ the field of personalised cancer treatment is evolving and further studies should consider the molecular profile of the tumour. Additional molecular pathological epidemiology studies assessing CRC risk and progression could provide further insights into the anti-cancer effect of statins and identify potential biomarkers to tailor treatment. ${ }^{45}$ In particular TP53 mutations, ${ }^{46}$ immunohistochemical expression of hydroxymethylglutaryl-CoA reductase ${ }^{47,48}$ and single nucleotide polymorphisms in the genes which encode proteins involved in statin metabolism ${ }^{48}$ have been identified as potential biomarkers to differentiate potentially statin sensitive tumours and warrant further study.

The strengths of the Scottish cohort study include its large population-based design and use of dispensing information with detailed information on the type, timing and dose of statins being used. One of the main limitations is that this is an observational 
study and there is the potential for residual confounding for which we could not control. The follow-up period was also relatively short (average 3.4 years from diagnosis with 2.4 years of follow-up) and may not be sufficient to fully assess the potential beneficial effect of statins. However, three studies included in the review have similar follow-up periods (average/median 3.4-3.8 years), ${ }^{11,18,40}$ two of which demonstrated a survival benefit for post-diagnostic statin use and overall mortality. ${ }^{18,40}$ While dispensing information is more robust than prescribing information, compliance cannot be confirmed. Cause of death can also be misclassified when relying on data from national statistics records. ${ }^{8}$ Healthy-user bias $^{49}$ could be responsible for the observed improvement in survival for prediagnostic users but co-morbidities were actually higher in statin users. Finally, statin users had a smaller proportion of Dukes' C cancers but the adjusted analyses should correct for this difference.

Compared to prior systematic reviews and meta-analyses, ${ }^{20-22}$ the present updated one benefits from the ability to include data from the Scottish cohort study and at least five further studies. ${ }^{19,39-42}$ The three previous reviews ${ }^{20-22}$ also incorporated results from one study ${ }^{13}$ identified as being at risk of immortal time bias, ${ }^{10,20}$ whereas it was excluded from our pooled analysis. In addition, the review by Zhong et al. ${ }^{20}$ excluded the estimate reported by Nielsen et al. ${ }^{8}(n=43,487$ patients) for colon cancer-specific mortality and pre-diagnostic statin use despite identifying the study. The review by Ling et al. ${ }^{21}$ included the HR from both the nationwide cohort study and nested matched study reported by Nielsen et al. ${ }^{8}$ adding inappropriate extra weight to this study as individuals were counted twice. Finally Ling et al. ${ }^{21}$ and Cai et al. ${ }^{22}$ have misclassified the HR for overall mortality reported by Siddiqui et al. ${ }^{17}$ as 
cancer-specific mortality. Therefore, we believe our review adds improved rigour to prior systematic evaluations of this topic.

In summary, combining the results of this cohort study and the updated systematic review and meta-analysis suggests that statin use appears to be associated with reduced mortality in CRC. However the magnitude of the effect is weak and the association may not be causal. The association also varies markedly between studies for statin use after diagnosis, the only time point at which clinical intervention is possible. Importantly, the only RCT assessing adjuvant statin therapy after surgery for early stage colon cancer (NCT01011478) ${ }^{50}$ has been terminated due to poor accrual (predominantly due to limited numbers of statin-naïve patients - personal communication, NSABP, 2015). To inform the decision to conduct future trials, further observational studies reporting cancer-specific survival outcomes are therefore required to clarify the association between post-diagnostic statin use and CRC-specific survival. 


\section{ACKNOWLEDGEMENTS}

The authors would like to thank the research coordinators (Lizzie Nicholson and

David Bailey) and NHS National Services Scotland for facilitating access and analysis of the Scottish cohort. We would also like to thank Dr Marjolein Zanders (Department of Research, Netherlands Comprehensive Cancer Organisation, Netherlands), Dr Eric Anderson (Department of Radiation Oncology, Stanford University, USA), Professor James Hardwick (Department of Gastroenterology \& Hepatology, Leiden University Medical Center, Netherlands), Dr Sung Hee Lim (Division of Hematology-Oncology, Samsung Medical Centre, Sungkyunkwan University School of Medicine, Korea) and Dr Michael Vickers (The Ottawa Hospital Cancer Centre, Canada) for kindly providing additional data for the pooled analysis and Dr Bun Kim (Center for Cancer Prevention and Detection, National Cancer Center, Goyang, Korea) for confirming the time of statin assessment.

\section{FINANCIAL SUPPORT}

Queen's University Belfast funded data access. R.T.G. is supported by a Health \& Social Care Research and Development Division of the Public Health Agency (HSC R\&D Division) Doctoral Fellowship. H.G.C. is supported by a Cancer Research UK Population Health Postdoctoral Fellowship. The funding sources had no involvement in study design, data collection and analysis, writing the manuscript or the decision to submit the article for publication. 


\section{REFERENCES}

1. Ferlay J, Soerjomataram I, Ervik M, et al. GLOBOCAN 2012 v1.0, Cancer Incidence and Mortality Worldwide: IARC CancerBase No. 11. 2013. Available at: http://globocan.iarc.fr/Pages/fact_sheets_cancer.aspx? Accessed January $10,2015$.

2. Cancer Research UK. Bowel cancer Key Stats. Available at: http://publications.cancerresearchuk.org/cancerstats/statsbowel/keyfactsbowel .html. Accessed January 21, 2015.

3. Coleman M, Forman D, Bryant $\mathrm{H}$, et al. Cancer survival in Australia, Canada, Denmark, Norway, Sweden, and the UK, 1995-2007 (the International Cancer Benchmarking Partnership): an analysis of population-based cancer registry data. Lancet. 2011;377(9760):127-138.

4. Andre T, Boni C, Mounedji-Boudiaf L, et al. Oxaliplatin, fluorouracil, and leucovorin as adjuvant treatment for colon cancer. $N$ Engl $\mathrm{J}$ Med. 2004;350(23):2343-2351.

5. Gustavsson B, Carlsson G, Machover D, et al. A Review of the evolution of systemic chemotherapy in the management of colorectal cancer. Clin Colorectal Cancer. 2015;14(1):1-10.

6. Domingo E, Church DN, Sieber O, et al. Evaluation of PIK3CA mutation as a predictor of benefit from nonsteroidal anti-inflammatory drug therapy in colorectal cancer. J Clin Oncol. 2013;31(34):4297-4305.

7. Li $\mathrm{P}, \mathrm{Wu} \mathrm{H}$, Zhang $\mathrm{H}$, et al. Aspirin use after diagnosis but not prediagnosis improves established colorectal cancer survival: a meta-analysis. Gut. 
2015;64(9):1419-1425.

8. Nielsen SF, Nordestgaard BG, Bojesen SE. Statin use and reduced cancerrelated mortality. N Engl J Med. 2012;367(19):1792-802.

9. Bardou M, Barkun A, Martel M. Effect of statin therapy on colorectal cancer. Gut. 2010;59(11):1572-1585.

10. Cardwell CR, Hicks BM, Hughes C, Murray LJ. Statin use after colorectal cancer diagnosis and survival: a population-based cohort study. J Clin Oncol. 2014;32(28):3177-3183.

11. Hoffmeister M, Jansen L, Rudolph A, et al. Statin use and survival after colorectal cancer: the importance of comprehensive confounder adjustment. $J$ Natl Cancer Inst. 2015;107(6):djv045.

12. Krens LL, Simkens LHJ, Baas JM, et al. Statin use is not associated with improved progression free survival in cetuximab treated KRAS mutant metastatic colorectal cancer patients: results from the CAIRO2 study. PLoS One. 2014;9(11):e112201.

13. Lakha F, Theodoratou E, Farrington SM, et al. Statin use and association with colorectal cancer survival and risk: case control study with prescription data linkage. BMC Cancer. 2012;12:487. doi:10.1186/1471-2407-12-487.

14. Mace AG, Gantt GA, Skacel M, Pai R, Hammel JP, Kalady MF. Statin therapy is associated with improved pathologic response to neoadjuvant chemoradiation in rectal cancer. Dis Colon Rectum. 2013;56(11):1217-27.

15. $\mathrm{Ng} \mathrm{K}$, Ogino S, Meyerhardt JA, et al. Relationship between statin use and colon cancer recurrence and survival: results from CALGB 89803. J Natl 
Cancer Inst. 2011;103(20):1540-1551.

16. Shao $\mathrm{YY}, \mathrm{Hsu} \mathrm{CH}$, Yeh $\mathrm{KH}$, et al. Statin use is associated with improved prognosis of colorectal cancer in Taiwan. Clin Colorectal Cancer. 2015;14(3):177-184.

17. Siddiqui AA, Nazario H, Mahgoub A, Patel M, Cipher D, Spechler SJ. For patients with colorectal cancer, the long-term use of statins is associated with better clinical outcomes. Dig Dis Sci. 2009;54(6):1307-11.

18. Zanders MMJ, van Herk-Sukel MPP, Vissers PAJ, Herings RMC, Haak HR, van de Poll-Franse $L$ V. Statin use as a moderator of metformin effect on overall survival in colorectal cancer patients with diabetes. $\mathrm{Br} \mathrm{J}$ Cancer. 2015;113:403-410.

19. Anderson E, Von Eyben R, Kozak M, et al. Statin use as a predictor of outcome in colorectal cancer. Int J Radiat Oncol Biol Phys. 2014;90(1 SUPPL. 1):S395-S396.

20. Zhong S, Zhang X, Chen L, Ma T, Tang J, Zhao J. Statin use and mortality in cancer patients: systematic review and meta-analysis of observational studies. Cancer Treat Rev. 2015;41(6):554-67.

21. Ling $\mathrm{Y}$, Yang $\mathrm{L}$, Huang $\mathrm{H}$, et al. Prognostic Significance of Statin Use in Colorectal Cancer. Medicine (Baltimore). 2015;94(25):e908.

22. Cai H, Zhang G, Wang Z, Luo Z, Zhou X. Relationship Between the Use of Statins and Patient Survival in Colorectal Cancer: A Systematic Review and Meta-Analysis. PLoS One. 2015;10(6):e0126944. doi:10.1371/journal.pone.0126944. 
23. Lévesque LE, Hanley JA, Kezouh A, Suissa S. Problem of immortal time bias in cohort studies: example using statins for preventing progression of diabetes. BMJ. 2010;340:b5087.

24. Alvarez-Madrazo S, McTaggart S, Nangle C, Nicholson E, Bennie M. Data resource profile: the Scottish national Prescribing Information System (PIS). Int J Epidemiol. 2016;45(3):714-715f.

25. Chubak J, Boudreau DM, Wirtz HS, McKnight B, Weiss NS. Threats to validity of nonrandomized studies of postdiagnosis exposures on cancer recurrence and survival. J Natl Cancer Inst. 2013;105(19):1456-1462.

26. Joint Formulary Committe. British National Formulary (Online). London: BMJ Group and Pharmaceutical Press Available at: http://www.medicinescomplete.com. Accessed September 14, 2014.

27. WHO Collaborating Centre for Drug Statistics Methodology. Guidelines for ATC Classification and DDD Assignment, 2015. Oslo; 2014. Available at: http://www.whocc.no/atc_ddd_publications/guidelines/. Accessed November 9, 2015.

28. Sundararajan V, Henderson T, Perry C, Muggivan A, Quan H, Ghali WA. New ICD-10 version of the Charlson comorbidity index predicted in-hospital mortality. J Clin Epidemiol. 2004;57(12):1288-94.

29. The Scottish Government. Scottish Index of Multiple Deprivation 2009: General Report. A Scottish Government National Statistics Publication Available at: http://www.gov.scot/Publications/2009/10/28104046/0. Accessed September 14, 2014. 
30. Zhou Z, Rahme E, Abrahamowicz M, Pilote L. Survival bias associated with time-to-treatment initiation in drug effectiveness evaluation: A comparison of methods. Am J Epidemiol. 2005;162(10):1016-1023.

31. Schisterman EF, Cole SR, Platt RW. Overadjustment bias and unnecessary adjustment in epidemiologic studies. Epidemiology. 2009;20(4):488-495.

32. Weinberg CR. Toward a clearer definition of confounding. Am J Epidemiol. 1993;137(1):1-8.

33. Moher D, Liberati A, Tetzlaff J, Altman DG. Preferred reporting items for systematic reviews and meta-analyses. BMJ. 2009;338:b2535.

34. Stroup DF, Berlin JA, Morton SC, et al. Meta-analysis of observational studies in epidemiology: a proposal for reporting. JAMA. 2000;283(15):2008-12.

35. Wells G, Shea B, O'Connell D, et al. The Newcastle-Ottawa Scale (NOS) for assessing the quality of nonrandomized studies in meta-analyses. Available at: http://www.ohri.ca/programs/clinical_epidemiology/oxford.asp. Accessed March 16, 2015.

36. Higgins J, Green S, eds. Cochrane Handbook for Systematic Reviews of Interventions Version 5.1.0 [Updated March 2011]. The Cochrane Collaboration; 2011. Available at: Available from www.cochrane-handbook.org. Accessed March 16, 2015.

37. Parmar MK, Torri V, Stewart L. Extracting summary statistics to perform metaanalyses of the published literature for survival endpoints. Stat Med. 1998;17(24):2815-34.

38. Higgins JPT, Thompson SG, Deeks JJ, Altman DG. Measuring inconsistency 
in meta-analyses. BMJ. 2003;327(7414):557-560.

39. Lim SH, Kim TW, Hong YS, et al. A randomised, double-blind, placebocontrolled multi-centre phase III trial of XELIRI/FOLFIRI plus simvastatin for patients with metastatic colorectal cancer. Br J Cancer. 2015;113(10):14211426.

40. Voorneveld P, Reimers MS, Jacobs RJ, et al. Statin use after diagnosis improves survival in colorectal cancer patients [abstract]. Gastroenterology. $2015 ; 148(4,1): S 951$.

41. Armstrong D, Raissouni S, Price Hiller J, et al. Predictors of pathologic complete response after neoadjuvant treatment for rectal cancer: A multicenter study. Clin Colorectal Cancer. 2015;14(4):291-5.

42. Kim B, Park SJ, Hong SP, Cheon JH, Kim WH, Kim T II. The effect of prediagnostic aspirin use on the prognosis of stage III colorectal cancer. Int $\mathrm{J}$ Clin Exp Med. 2015;8(8):13435-13445.

43. National Services Division. Scottish Bowel Screening Programme. Available at: http://www.nsd.scot.nhs.uk/services/Screening/bowelscreening/index.html. Accessed January 21, 2016.

44. National Institute for Health and Care Excellence. Capecitabine and Oxaliplatin in the Adjuvant Treatment of Stage III (Dukes' C) Colon Cancer (TA100). Available at: https://www.nice.org.uk/guidance/ta100/chapter/About-thisguidance. Accessed January 21, 2016.

45. Lee JE, Baba $\mathrm{Y}, \mathrm{Ng} \mathrm{K}$, et al. Statin use and colorectal cancer risk according to molecular subtypes in two large prospective cohort studies. Cancer Prev Res. 
2011;4(11):1808-15.

46. Freed-Pastor WA, Mizuno $\mathrm{H}$, Zhao X, et al. Mutant p53 disrupts mammary tissue architecture via the mevalonate pathway. Cell. 2012;148(1-2):244-58.

47. Bengtsson E, Nerjovaj P, Wangefjord S, et al. HMG-CoA reductase expression in primary colorectal cancer correlates with favourable clinicopathological characteristics and an improved clinical outcome. Diagn Pathol. 2014;9:78.

48. Ahern TP, Lash TL, Damkier P, Christiansen PM, Cronin-Fenton DP. Statins and breast cancer prognosis: evidence and opportunities. Lancet Oncol. 2014;15(10):e461-8.

49. Shrank WH, Patrick AR, Brookhart MA. Healthy user and related biases in observational studies of preventive interventions: a primer for physicians. $J$ Gen Intern Med. 2011;26(5):546-50.

50. National Surgical Adjuvant Breast and Bowel Project Foundation. Statin Polyp Prevention Trial in Patients with Resected Colon Cancer. Available at: https://clinicaltrials.gov/ct2/show/NCT01011478. Accessed December 2, 2015. 
Table 1. Characteristics of colorectal cancer patients by post-diagnostic statin use

\begin{tabular}{|c|c|c|c|c|}
\hline & \multicolumn{4}{|c|}{$\begin{array}{l}\text { Statin use in first year after } \\
\text { cancer diagnosis* }\end{array}$} \\
\hline & \multicolumn{2}{|c|}{ Yes } & \multicolumn{2}{|c|}{ No } \\
\hline & $\mathrm{n}$ & $\%$ & $\mathrm{n}$ & $\%$ \\
\hline \multicolumn{5}{|l|}{ Age } \\
\hline$<50$ & 20 & 0.6 & 425 & 8.1 \\
\hline $50-59$ & 248 & 7.9 & 996 & 19.0 \\
\hline $60-69$ & 927 & 29.6 & 1,632 & 31.1 \\
\hline $70-79$ & 1,348 & 43.0 & 1,462 & 27.8 \\
\hline$\geq 80$ & 594 & 18.9 & 739 & 14.1 \\
\hline Men & 1,913 & 61.0 & 2,761 & 52.6 \\
\hline \multicolumn{5}{|l|}{ Deprivation (fifth) } \\
\hline 1 (most deprived) & 632 & 20.1 & 854 & 16.3 \\
\hline 2 & 711 & 22.7 & 1,058 & 20.1 \\
\hline 3 & 618 & 19.7 & 1,074 & 20.4 \\
\hline 4 & 641 & 20.4 & 1,132 & 21.5 \\
\hline 5 (least deprived) & 535 & 17.1 & 1,135 & 21.6 \\
\hline Colon & 2204 & 70.3 & 3,516 & 66.9 \\
\hline Rectum $^{\dagger}$ & 933 & 29.7 & 1,738 & 33.1 \\
\hline \multicolumn{5}{|l|}{ Dukes' stage } \\
\hline$A$ & 931 & 29.7 & 1,349 & 25.7 \\
\hline $\mathrm{B}$ & 1,187 & 37.8 & 2,004 & 38.1 \\
\hline $\mathrm{C}$ & 1,019 & 32.5 & 1,901 & 36.2 \\
\hline \multicolumn{5}{|l|}{ Grade } \\
\hline Well differentiated & 119 & 3.8 & 166 & 3.2 \\
\hline Moderately differentiated & 2,450 & 78.1 & 3,992 & 76.0 \\
\hline Poorly differentiated & 432 & 13.8 & 851 & 16.2 \\
\hline Missing & 136 & 4.3 & 245 & 4.7 \\
\hline \multicolumn{5}{|l|}{ Treatment (within 6 months) } \\
\hline Surgery & 2,972 & 94.7 & 4,956 & 94.3 \\
\hline Radiotherapy & 258 & 8.2 & 613 & 11.7 \\
\hline Chemotherapy & 693 & 22.1 & 1,946 & 37.0 \\
\hline \multicolumn{5}{|c|}{ Comorbidity before cancer diagnosis } \\
\hline Acute myocardial infarction & 352 & 11.2 & 51 & 1.0 \\
\hline Congestive heart failure & 166 & 5.3 & 63 & 1.2 \\
\hline Peripheral vascular disease & 181 & 5.8 & 44 & 0.8 \\
\hline Cerebral vascular accident & 244 & 7.8 & 59 & 1.1 \\
\hline Pulmonary disease & 277 & 8.8 & 313 & 6.0 \\
\hline Peptic ulcer & 101 & 3.2 & 109 & 2.1 \\
\hline Liver disease & 7 & 0.2 & 24 & 0.5 \\
\hline Diabetes & 467 & 14.9 & 108 & 2.1 \\
\hline Renal disease & 109 & 3.5 & 80 & 1.5 \\
\hline Aspirin use & $1,647^{a}$ & $52.5^{a}$ & $503^{a}$ & $9.6^{a}$ \\
\hline
\end{tabular}

* Restricted to patients who survived at least one year after diagnosis †'Includes recto sigmoid junction $a-$ Refers to aspirin use in the year after diagnosis Abbreviation: $\mathrm{n}$ - number. 
Table 2. Association between statin use after diagnosis and cancer-specific and all-cause mortality in patients with colorectal cancer.

$\begin{array}{lllclcc}\text { Mortality } & \text { Patients } & \begin{array}{c}\text { Person } \\ \text { Years }\end{array} & \begin{array}{c}\text { Unadjusted HR } \\ (95 \% \mathrm{Cl})\end{array} & \mathrm{P} & \begin{array}{c}\text { Adjusted }^{1} \mathrm{HR} \\ (95 \% \mathrm{Cl})\end{array} & \mathrm{P} \\ & & & \end{array}$

\begin{tabular}{|c|c|c|c|c|c|c|c|}
\hline \multicolumn{8}{|c|}{ Cancer-specific mortality } \\
\hline Statin non-user & 639 & 4,766 & 13,224 & 1.00 (ref. cat.) & & 1.00 (ref. cat.) & \\
\hline Statin user & 425 & 3,625 & 8,910 & $1.01(0.89,1.14)$ & 0.89 & $0.90(0.77,1.05)$ & 0.17 \\
\hline $\begin{array}{l}\text { 1-12 prescriptions vs. } \\
\text { non-user }\end{array}$ & 257 & 1,199 & 4,927 & $1.00(0.86,1.16)$ & 0.98 & $0.89(0.75,1.06)$ & 0.19 \\
\hline $\begin{array}{l}\geq 12 \text { prescriptions vs. } \\
\text { non-user }\end{array}$ & 168 & 2,426 & 3,983 & $1.03(0.86,1.23)$ & 0.78 & $0.91(0.74,1.12)$ & 0.39 \\
\hline $\begin{array}{l}1 \text { to } 365 \text { DDDs vs. } \\
\text { non-user }\end{array}$ & 271 & 1,470 & 5,196 & $1.02(0.89,1.18)$ & 0.75 & $0.90(0.77,1.07)$ & 0.23 \\
\hline $\begin{array}{l}\geq 365 \text { DDDs vs. non- } \\
\text { user }\end{array}$ & 154 & 2,155 & 3,714 & $0.98(0.82,1.18)$ & 0.85 & $0.90(0.72,1.10)$ & 0.29 \\
\hline Simvastatin non-user & 761 & 5,789 & 15,799 & 1.00 (ref. cat.) & & 1.00 (ref. cat.) & \\
\hline Simvastatin user & 303 & 2,602 & 6,335 & $1.02(0.89,1.17)$ & 0.76 & $0.96(0.83,1.12)$ & 0.63 \\
\hline \multicolumn{8}{|c|}{ Overall mortality } \\
\hline Statin non-user & 906 & 4,766 & 13,224 & 1.00 (ref. cat.) & & 1.00 (ref. cat.) & \\
\hline Statin user & 729 & 3,625 & 8,910 & $1.20(1.09,1.33)$ & $<0.001$ & $0.90(0.80,1.02)$ & 0.09 \\
\hline $\begin{array}{l}1-12 \text { prescriptions vs. } \\
\text { non-user }\end{array}$ & 405 & 1,199 & 4,927 & $1.16(1.03,1.30)$ & 0.02 & $0.89(0.78,1.02)$ & 0.11 \\
\hline $\begin{array}{l}\geq 12 \text { prescriptions vs. } \\
\text { non-user }\end{array}$ & 324 & 2,426 & 3,983 & $1.27(1.11,1.45)$ & 0.001 & $0.91(0.78,1.07)$ & 0.25 \\
\hline $\begin{array}{l}1 \text { to } 365 \text { DDDs vs. } \\
\text { non-user }\end{array}$ & 436 & 1,470 & 5,196 & $1.21(1.07,1.35)$ & 0.001 & $0.91(0.80,1.04)$ & 0.18 \\
\hline $\begin{array}{l}\geq 365 \text { DDDs vs. non- } \\
\text { user }\end{array}$ & 293 & 2,155 & 3,714 & $1.21(1.05,1.38)$ & 0.007 & $0.88(0.75,1.03)$ & 0.11 \\
\hline Simvastatin non-user & 1,126 & 5,789 & 15,799 & 1.00 (ref. cat.) & & 1.00 (ref. cat.) & \\
\hline Simvastatin user & 509 & 2,602 & 6,335 & $1.14(1.02,1.26)$ & 0.02 & $0.94(0.83,1.05)$ & 0.26 \\
\hline
\end{tabular}

\footnotetext{
${ }^{1}$ Model contains age, sex, year of diagnosis, deprivation, site (colon or rectum), stage, grade, cancer treatment within 6 months (radiotherapy, chemotherapy, surgery), comorbidities (prior to diagnosis, including acute myocardial infarction, congestive heart failure, peripheral vascular disease, cerebral vascular accident, pulmonary disease, peptic ulcer, liver disease, diabetes, renal disease) and aspirin use (as time-varying covariate).
} 
Table 3. Sensitivity analysis of association between statin use and cancer-specific and all-cause mortality in patients with colorectal cancer.

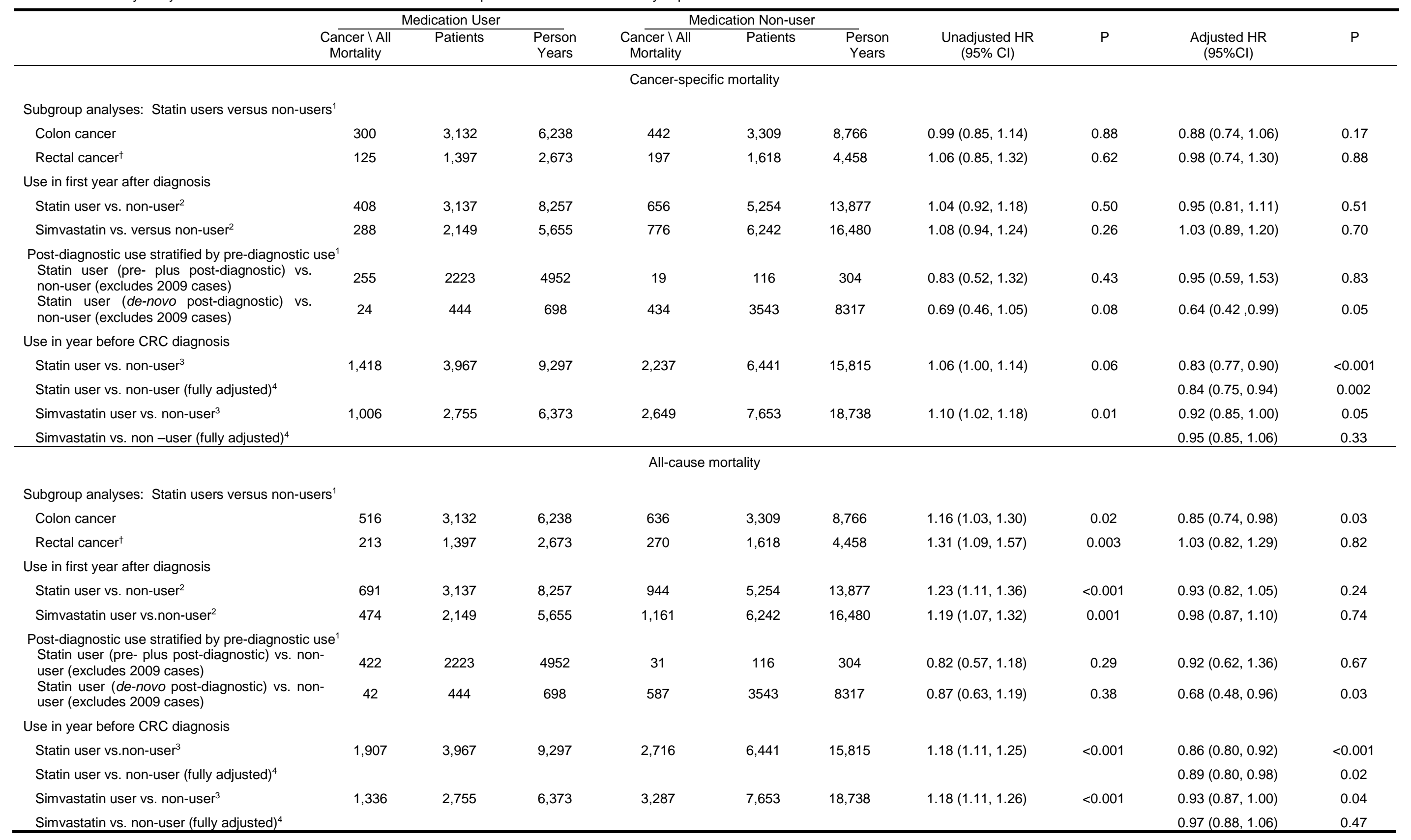




\section{${ }^{\dagger}$ Includes rectosigmoid junction}

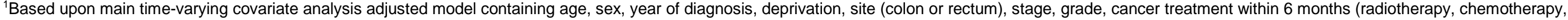

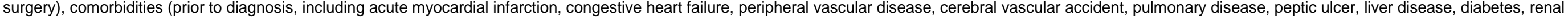
disease) and aspirin use (as time-varying covariate).

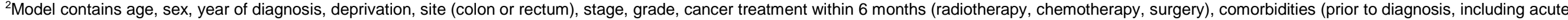

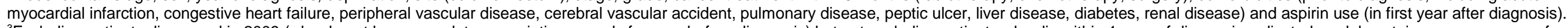

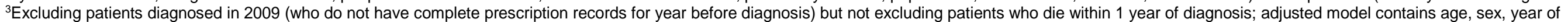

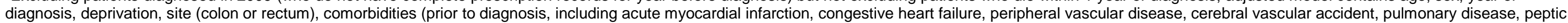
ulcer, liver disease, diabetes, renal disease) and aspirin use (in year prior to diagnosis).

${ }^{4}$ Adjusting for variables in (3) but additionally adjusting for stage, grade and cancer treatment within 6 months (radiotherapy, chemotherapy, surgery). 


\begin{tabular}{|c|c|c|c|c|c|c|c|c|}
\hline $\begin{array}{l}\text { First Author (year) } \\
\text { Country }\end{array}$ & $\begin{array}{l}\text { Study design } \\
\text { (Exposure Ascertainment) }\end{array}$ & $\begin{array}{l}\text { Study Period } \\
\text { (Follow-up) }\end{array}$ & $\begin{array}{l}\text { No. of } \\
\text { Patients }\end{array}$ & $\begin{array}{l}\text { Tumour } \\
\text { Location }\end{array}$ & Stage & $\begin{array}{c}\text { Statin } \\
\text { Use }\end{array}$ & Outcome & Adjusted Variables \\
\hline $\begin{array}{l}\text { Lim }(2015)^{39} \\
\text { Korea }\end{array}$ & $\begin{array}{l}\text { RCT } \\
(\mathrm{N} / \mathrm{A})\end{array}$ & $\begin{array}{l}2010-2013 \\
(N R)\end{array}$ & 269 & CRC & IV & Post & $\mathrm{OM}^{\pi}$ & Unadjusted hazard ratio provided by the study authors through personal communication. \\
\hline $\begin{array}{l}\text { Current study } \\
\text { Scotland }\end{array}$ & $\begin{array}{l}\text { Prospective population- } \\
\text { based cohort } \\
\text { (Dispensing database) }\end{array}$ & $\begin{array}{l}\text { 2009-2012 } \\
\text { (Censored 2015, } \\
\text { mean 3.4 years) }\end{array}$ & 8391 & CRC & I-III & Post & $\begin{array}{l}\text { CSM } \\
\& \\
\mathrm{OM}\end{array}$ & $\begin{array}{l}\text { Age, sex, year of diagnosis, deprivation, site (colon or rectum), stage, grade, cancer treatment within } 6 \text { months } \\
\text { (radiotherapy, chemotherapy, surgery), comorbidities (prior to diagnosis, including acute myocardial infarction, } \\
\text { congestive heart failure, peripheral vascular disease, cerebral vascular accident, pulmonary disease, peptic ulcer, } \\
\text { liver disease, diabetes, renal disease) and aspirin use (as time-varying covariate). }\end{array}$ \\
\hline $\begin{array}{l}\text { Cardwell }(2014)^{10} \\
\text { England }\end{array}$ & $\begin{array}{l}\text { Prospective population- } \\
\text { based cohort } \\
\text { (Prescribing database) }\end{array}$ & $\begin{array}{l}\text { 1998-2009 } \\
\text { (Censored 2012, } \\
\text { mean } 5 \text { years) }\end{array}$ & 7657 & $\mathrm{CRC}$ & I-III & $\begin{array}{l}\text { Pre } \\
\& \\
\text { Post }^{\dagger}\end{array}$ & $\begin{array}{l}\text { CSM } \\
\& \\
\text { OM }\end{array}$ & $\begin{array}{l}\text { Year of diagnosis, age at diagnosis, sex, stage, surgery within } 6 \text { months, radiotherapy within } 6 \text { months, } \\
\text { chemotherapy within } 6 \text { months, site, comorbidities, low-dose aspirin, ACEls, and metformin use after diagnosis as } \\
\text { time-varying covariates, grade, deprivation, and smoking before diagnosis. Post- but not pre-diagnostic analyses } \\
\text { adjusted for stage and grade as potentially on causal pathway. }\end{array}$ \\
\hline $\begin{array}{l}\text { Hoffmeister }(2015)^{11} \\
\text { Germany }\end{array}$ & $\begin{array}{l}\text { Prospective population- } \\
\text { based cohort } \\
\text { (Patient reported) }\end{array}$ & $\begin{array}{l}2003-2009 \\
\text { (Median } 3.4 \\
\text { years) }\end{array}$ & 2697 & CRC & I-IV & $\mathrm{Post}^{\ddagger}$ & $\begin{array}{l}\text { CSM } \\
\& \\
\text { OM }\end{array}$ & $\begin{array}{l}\text { Age at diagnosis, sex, stage, site, surgery, neoadjuvant treatment, chemotherapy, radiotherapy, BMI, lifetime pack- } \\
\text { years of active smoking, physical activity, diabetes, ever regular use of NSAIDs including aspirin, ever use of HRT } \\
\text { among women, previous large bowel endoscopy, hypercholesterolemia, myocardial infarction, stroke, heart failure, } \\
\text { participation in general health check-ups, late entry into the study, and time-dependent effect chemotherapy. }\end{array}$ \\
\hline $\begin{array}{l}\text { Nielsen }(2012)^{8} \\
\text { Denmark }\end{array}$ & $\begin{array}{l}\text { Prospective population- } \\
\text { based cohort } \\
\text { (Dispensing database) }\end{array}$ & $\begin{array}{l}1995-2007 \\
\text { (Censored 2009) }\end{array}$ & 43487 & Colon & NR & Pre & CSM & $\begin{array}{l}\text { Age at diagnosis, stage, chemotherapy, radiotherapy, cardiovascular disease, diabetes mellitus, year of birth, sex, } \\
\text { descent, education, and size of residential area. }{ }^{\star} \text { Tumour staging only available for } 3 \text { years (2004-2007). }\end{array}$ \\
\hline $\begin{array}{l}\text { Shao }(2015)^{16} \\
\text { Taiwan }\end{array}$ & $\begin{array}{l}\text { Prospective population- } \\
\text { based cohort } \\
\text { (Insurance database) }\end{array}$ & $\begin{array}{l}\text { 2004-2008 } \\
\text { (Censored 2011, } \\
\text { median } 4.2 \text { years) }\end{array}$ & 17115 & CRC & I-III & Pre & $\begin{array}{l}\text { CSM } \\
\& \\
\mathrm{OM}\end{array}$ & $\begin{array}{l}\text { Age, sex, tumour stage, adjuvant therapy and a propensity score for statin use modelled on age, sex, year of } \\
\text { diagnosis, physician visits and hospitalisation } 1 \text { year prior to diagnosis, aspirin, NSAIDs, insulin, oral anti-diabetic } \\
\text { medication, ACEIs, ARBs and comorbidities. }\end{array}$ \\
\hline $\begin{array}{l}\text { Zanders }(2015)^{18} \\
\text { Netherlands }\end{array}$ & $\begin{array}{l}\text { Prospective population- } \\
\text { based cohort } \\
\text { (Dispensing database) }\end{array}$ & $\begin{array}{l}\text { 1998-2011 } \\
\text { (Censored 2011, } \\
\text { mean } 3.4 \text { years) }\end{array}$ & 1043 & CRC & I-IV & Post $^{\dagger}$ & $\mathrm{OM}^{\pi}$ & $\begin{array}{l}\text { Metformin, sulfonylurea derivatives, insulin, other diabetes medication, statins and aspirin after diagnosis as time- } \\
\text { dependent ever-never terms, the use of these drugs before diagnosis as a dichotomised variable, and the time- } \\
\text { fixed variables: sex, age at CRC diagnosis, calendar year of CRC diagnosis, type of CRC, stage and administration } \\
\text { of surgery, radiotherapy and/or chemotherapy. }\end{array}$ \\
\hline $\begin{array}{l}\text { Voorneveld }(2015)^{40} \\
\text { Netherlands }\end{array}$ & $\begin{array}{l}\text { Prospective population- } \\
\text { based cohort } \\
\text { (Dispensing database) }\end{array}$ & $\begin{array}{l}1998-2007 \\
\text { (Censored 2012, } \\
\text { median } 3.8 \text { years) }\end{array}$ & 999 & Colon & $\mathrm{I}-\mathrm{IV}$ & Post $^{\dagger}$ & $O M^{\pi}$ & $\begin{array}{l}\text { Unadjusted hazard ratio estimated using Parmar's method based on the log rank test provided through personal } \\
\text { communication. }\end{array}$ \\
\hline $\begin{array}{l}\text { Krens }(2014)^{12} \\
\text { Netherlands }\end{array}$ & $\begin{array}{l}\text { Prospective cohort within } \\
\text { RCT (Patient reported) }\end{array}$ & $\begin{array}{l}2005-2006 \\
\quad(N R)\end{array}$ & 529 & $\mathrm{CRC}$ & IV & Post $^{\ddagger}$ & OM & $\begin{array}{l}\text { Age, prior adjuvant therapy, aspirin use, }>1 \text { organ affected by metastatic spread, treatment arm, KRAS mutation } \\
\text { status, and a KRAS*statin interaction term. }\end{array}$ \\
\hline $\begin{array}{l}\mathrm{Ng}(2011)^{15} \\
\text { USA }\end{array}$ & $\begin{array}{l}\text { Prospective cohort within } \\
\text { RCT } \\
\text { (Patient reported) }\end{array}$ & $\begin{array}{l}1999-2001 \\
\text { (Censored 2009, } \\
\text { median } 6.5 \text { years) }\end{array}$ & 842 & Colon & III & Post $^{\ddagger}$ & OM & $\begin{array}{l}\text { Age, sex, family history of colorectal cancer, ECOG performance status ( } 0 \text { vs. } 1-2) \text {, T stage }(\mathrm{T} 1 / \mathrm{T} 2 \mathrm{vs} \text {. T3/T4), } \\
\text { number of positive lymph nodes ( }(1-3 \mathrm{vs} \text {. } \geq 4) \text {, perineural invasion, extravascular invasion, postoperative CEA }(<5 \mathrm{vs.} \text {. } \\
\geq 5 \mathrm{ng} / \mathrm{mL}) \text {, treatment arm, BMI, physical activity, Western pattern diet, KRAS mutation status, and aspirin use. }\end{array}$ \\
\hline $\begin{array}{l}\text { Lakha }(2012)^{13} \\
\text { Scotland }\end{array}$ & $\begin{array}{l}\text { Prospective cohort within } \\
\text { case-control study } \\
\text { (Dispensing database) }\end{array}$ & $\begin{array}{c}1999-2006 \\
\text { (Censored 2009) }\end{array}$ & 309 & CRC & $\mathrm{I}-\mathrm{IV}$ & $\begin{array}{l}\text { Pre } \\
\& \\
\text { Post }^{\S}\end{array}$ & $\begin{array}{l}\text { CSM } \\
\& \\
\text { OM }\end{array}$ & Stage, age, and sex. \\
\hline $\begin{array}{l}\text { Anderson }(2014)^{19} \\
\text { USA }\end{array}$ & $\begin{array}{l}\text { Retrospective cohort } \\
\text { (Medical record review) }\end{array}$ & $\begin{array}{l}\text { 2005-2009 } \\
\text { (Censored 2013) }\end{array}$ & 230 & CRC & I-IV & Post $^{\ddagger}$ & $\mathrm{OM}^{\pi}$ & Age at diagnosis, stage, margin status and chemotherapy use. \\
\hline
\end{tabular}




\begin{tabular}{|c|c|c|c|c|c|c|c|c|}
\hline $\begin{array}{l}\text { First Author (year) } \\
\text { Country }\end{array}$ & $\begin{array}{l}\text { Study design } \\
\text { (Exposure Ascertainment) }\end{array}$ & $\begin{array}{l}\text { Study Period } \\
\text { (Follow-up) }\end{array}$ & $\begin{array}{l}\text { No. of } \\
\text { Patients }\end{array}$ & $\begin{array}{l}\text { Tumour } \\
\text { Location }\end{array}$ & Stage & $\begin{array}{l}\text { Statin } \\
\text { Use }\end{array}$ & Outcome & Adjusted Variables \\
\hline $\begin{array}{l}\text { Armstrong }(2015)^{41} \\
\text { Canada }\end{array}$ & $\begin{array}{l}\text { Retrospective cohort } \\
\text { (Medical record review) }\end{array}$ & $\begin{array}{c}2005-2012 \\
\text { (Median } 3.7 \text { years) }\end{array}$ & 891 & Rectum & I-IIII & Pre & $\mathrm{OM}^{\pi}$ & Age at diagnosis, pathologic stage, performance status, sex and adjuvant chemotherapy use \\
\hline $\begin{array}{l}\text { Kim }(2015)^{42} \\
\text { Korea }\end{array}$ & $\begin{array}{l}\text { Retrospective cohort } \\
\text { (Medical record review) }\end{array}$ & $\begin{array}{l}\text { 2007-2009 } \\
\quad(N R)\end{array}$ & 239 & CRC & III & Post & CSM & $\begin{array}{l}\text { Age, sex, comorbidity, pre-diagnosis aspirin use, medication, cancer site, initial stage and pathological } \\
\text { differentiation }\end{array}$ \\
\hline $\begin{array}{l}\text { Mace }(2013)^{14} \\
\text { USA }\end{array}$ & $\begin{array}{l}\text { Retrospective cohort } \\
\text { (Medical record review) }\end{array}$ & $\begin{array}{l}2000-2012 \\
\text { (Report } 5 \text { year } \\
\text { outcomes) }\end{array}$ & 394 & Rectum & I-IV & Post $^{\ddagger}$ & $\begin{array}{l}\text { CSM } \\
\& \\
\text { OM }\end{array}$ & Age, BMI, ASA class (III/IV vs. I/II), AJCC tumour regression grade, and stage. \\
\hline $\begin{array}{l}\text { Siddiqui }(2009)^{17} \\
\text { USA }\end{array}$ & $\begin{array}{l}\text { Retrospective cohort } \\
\text { (Dispensing database) }\end{array}$ & $\begin{array}{l}\text { 1997-2003 } \\
\text { (Report } 5 \text { year } \\
\text { outcomes) }\end{array}$ & 1309 & $\mathrm{CRC}$ & I-IV & Pre & $\begin{array}{l}\text { CSM } \\
\& \\
\text { OM }\end{array}$ & $\begin{array}{l}\text { Stage, anatomical site (right vs. other), presence of metastases, NSAIDs, and BMI for OM. } \\
\text { Unadjusted hazard ratio for CSM estimated using Parmar's method based on the log rank test reported in the } \\
\text { manuscript. }\end{array}$ \\
\hline
\end{tabular}

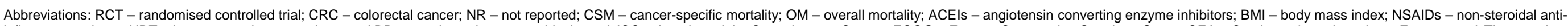

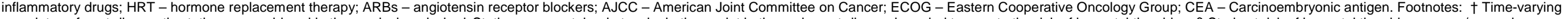

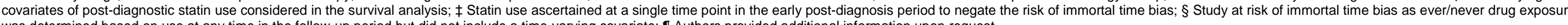
was determined based on use at any time in the follow-up period but did not include a time-varying covariate; $\uparrow$ Authors provided additional information upon request. 


\section{FIGURE LEGENDS}

Figure 1. Flow chart of the selection of publications included in the meta-analysis.

Figure 2. Forest plot of post-diagnostic statin use and $(A)$ colorectal cancer-specific survival and (B) overall survival. † - Parmar method used to estimate hazard ratio from log rank test; $\ddagger$ - Authors contacted for additional information including adjusted hazard ratios.

Figure 3. Forest plot of pre-diagnostic statin use and $(A)$ colorectal cancer-specific survival and (B) overall survival. † - Parmar method used to estimate hazard ratio from log rank test; $¥$ - Authors contacted for additional information including adjusted hazard ratios. 